\title{
LIST OF POSTER PAPERS
}

\section{Global Properties of the Photosphere}

ON THE ADIABATICITY OF THE SOLAR ATMOSPHERE FROM COMPARING LUMINOSITY AND VELOCITY MEASUREMENTS OF ACOUSTIC MODES

A. Jimenez ${ }^{1}$, M. Alvarez ${ }^{3}$, V. Domingo ${ }^{2}$, A. Jones $^{1}$, E. Ledezma ${ }^{3}$, P.L. Palle ${ }^{1}$

T. Roca Cortes ${ }^{1}$

${ }^{1}$ Instituto de Astrofisica de Canarias, E-38200 La Laguna, Tenerife, Spain

2 Space Science Department of ESA, ESTEC, Noordwijk, The Netherlands

3 Inst. de Astronomia, Observ. Astron. Nacional, Ensenada, Baja California, Mexico

NEW ABSOLUTE MEASUREMENTS OF THE SOLAR RADIATION

K.A. Burlov-Vasiljev, E.A. Gurtovenko, Yu.B. Matvejev, V.I. Trojan

Main Astronomical Observatory Ac.Sc. Ukr.SSR, Goloseevo, 252127 Kiev, USSR

PRECISION SPECTROPHOTOMETRY OF THE SUN AS A STAR

S.I. Gandzha, S.N. Osipov

Main Astronomical Observatory Ac.Sc. Ukr.SSR, Goloseevo, 252127 Kiev, USSR

ON THE DISTINCTION AND PHOTOSPHERIC DEPTHS OF THE PROCESSES FORMING A FRAUNHOFER LINE

E.A. Gurtovenko ${ }^{1}$, A.P. Sarychev ${ }^{2}$, V.A. Sheminova ${ }^{1}$

1 Main Astronomical Observatory Ac.Sc. Ukr.SSR, Goloseevo, 252127 Kiev, USSR

2 Sternberg State Astronomical Institute

Universitetsky Prospect, 13, 119899 Moscow, USSR

RESPONSE FUNCTIONS AND THEIR CAPABILITIES FOR DIAGNOSTICS OF VELOCITIES IN THE PHOTOSPHERE

V.N. Karpinsky, N.S. Petrova

Main Astronomical Observatory Ac.Sc. USSR, 196140 Leningrad, USSR

THE IRON IONIZATION EQUILIBRIUM IN THE SOLAR PHOTOSPHERE

J.H.M.J. Bruls

Astronomical Institute, NL-3508 TA Utrecht, The Netherlands

SOME ASPECTS OF ABUNDANCES DERIVED FROM THE SOLAR PHOTOSPHERIC SPECTRUM

B.T. Baij, M.B. Girnjak, M.M. Kovalchuk, P. Olijnyk, R. Rykaljuk

Astronomical Observatory of Lvov University, Lomonosov str. 8

Lvov 290005, USSR 
DETERMINATION OF MICROTURBULENT VELOCITIES IN THE SOLAR PHOTOSPHERE

A.V. Baranov

Solar Station, 692533 Ussurijsk, USSR

WEAK VIOLET CYANOGEN LINES AND THE VELOCITY FIELD IN THE SOLAR PHOTOSPHERE

G.A. Porfireva

Sternberg State Astronomical Institute, Moscow University, 119899 Moscow, USSR

PHOTOSPHERIC LINE REDSHIFTS FROM QUIET SUN ULTRAVIOLET SPECTRA

D. Samain

Institut d'Astrophys. Spatiale, B.P. 10, F-91371 Verrières-le-Buisson, France

PROFILES OF STRONG FRAUNHOFER LINES IN RESOLVED AND UNRESOLVED

SOLAR SPECTRA

J.M. Kuli-Zade

Azerbaijan State University, P.Lumumba, 23, 370073 Baku, USSR

Ca II EMISSION FROM THE SUN

R.J. Rutten, H. Uitenbroek

Astronomical Institute, NL-3508 TA Utrecht, The Netherlands

ON THE POSSIBILITY OF THE DEFINITION OF THE PHOTOSPHERE BRIGHTNESS DISTRIBUTION FROM ECLIPSE DATA

I.L. Belkina, N.P. Djatel, M.M. Pospergelis

Astronomical Observatory, Kharkov University, Sumskaya 35, Kharkov, USSR

SOLAR DIAMETER MEASUREMENTS WITH A SOLAR ASTROLABE

F. Laclare ${ }^{1}$, S. Debarbat ${ }^{2}$, A. Journet ${ }^{1}$, G. Merlin ${ }^{1}$

1 C.E.R.G.A., F-06130 Grasse, France

2 Observatoire de Paris, F-75014 Paris, France

OBSERVATIONS OF THE SUN AS A STAR AND THE MAPS OF CORONAL HOLES IN THE He I $10830 \AA$ LINE

E.V. Kondrashev

Main Astronomical Observatory Ac.Sc. USSR, Pulkovo, 196140 Leningrad, USSR

OBSERVATION OF SOLAR BRIGHTNESS FLUCTUATIONS WITH LOW SPATIAL

RESOLUTION

Yu.D. Zhugzhda, N. Lebedev

IZMIRAN, 142092 Troitsk, Moscow region, USSR

GLOBAL SOLAR OSCILLATIONS FROM OBSERVATIONS OF CONTINUUM BRIGHTNESS FLUCTUATIONS

Yu.D. Zhugzhda, N. Lebedev

IZMIRAN, 142092 Troitsk, Moscow region, USSR 


\section{Photospheric Fine Structure}

FAST LARGE-SCALE CHANGE IN THE NATURE OF THE SOLAR GRANULATION STRUCTURE

V.N. Karpinsky

Main Astronomical Observatory Ac.Sc. USSR, Pulkovo, 196140 Leningrad, USSR

STUDIES OF SOLAR GRANULATION USING 3-D FOURIER FILTERING

R.A. Shine, K.P. Topka, T.D. Tarbell, A.M. Title

Solar and Optical Physics Laboratory, O/91-30, B/256

Lockheed Palo Alto Research Lab., 3251 Hanover Street, Palo Alto, CA 94304, USA

SOLAR GRANULATION SPECTROMETRY

R.J. Rutten ${ }^{1}$, M. Carlsson ${ }^{2}$

1 Astronomical Institute, NL-3508 TA Utrecht, The Netherlands

2 Institute of Theoretical Astrophysics, N-0315 Oslo, Norway

PHOTOMETRY AND SPECTROSCOPY OF THE SOLAR GRANULATION ALONG THE POLAR AXIS AND EQUATOR

I. Rodriguez Hidalgo, M. Collados, M. Vazquez

Instituto de Astrofisica de Canarias, E-38200 La Laguna, Tenerife, Spain

SOLAR GRANULATION CONTRAST AND COLOR INDEX IN MAGNETIC AND NON-MAGNETIC REGIONS

C.U. Keller ${ }^{1}$, S. Koutchmy ${ }^{2}$

1 National Solar Observatory, Sunspot, NM 88349, USA and Institute of Astronomy, ETH-Zentrum, CH-8092 Zurich, Switzerland

2 AGFL/NSO-SP, Sunspot, NM 88349, USA and Institut d'Astrophysique, CNRS, 98 bis Bd Arago, F-75014 Paris, France

CONCERNING THE HEIGHT DISTRIBUTION OF VELOCITIES IN THE SOLAR GRANULATION

V.S. Markov

SibIZMIR, 664033 Irkutsk, USSR

THE INTERGRANULAR LANES IN THE QUIET SOLAR PHOTOSPHERE AS ORGANIZED STRUCTURES

S.I. Amalskaya

Main Astronomical Observatory Ac.Sc. USSR, Pulkovo, 196140 Leningrad, USSR

CONTINUOUS AND LINE SPECTRA OF GRANULES AND INTERGRANULAR LANES

Z. Suemoto, E. Hiei, Y. Nakagomi

National Astronomical Observatory, Mitaka, Tokyo-81, Japan

MULTIVARIATE ANALYSIS OF BIDIMENSIONAL SPECTROSCOPY OBSERVATIONS OF QUIET SOLAR REGIONS

B. Caccin ${ }^{1}$, G. Cauzzi ${ }^{2}$, R. Falciani ${ }^{3}$, M. Fofi ${ }^{4}$, L. Smaldone ${ }^{2}$

${ }^{1}$ Physics Department, II, University of Rome, Italy

2 Phys. Sciences Department, University of Naples, Italy

3 Astronomy Department, University of Florence, Italy

${ }^{4}$ Monte Mario Astronomical Observatory, Rome, Italy 
HIGH RESOLUTION SPECTROPOLARIMETRY OF AN ACTIVE REGION

D. Bonaccini ${ }^{1}$, E. Landi Degl'Innocenti ${ }^{2}$, L.J. November ${ }^{3}$, L.A. Smaldone ${ }^{4}$

1 Osservatorio Astrofisico di Arcetri, Largo E. Fermi 5, I-50125 Firenze, Italy

2 Dipartimento di Astronomia e Scienza dello Spazio, Università di Firenze I-50125 Firenze, Italy

3 NSO, P.O. Box 62, Sunspot, NM 88349, USA

${ }^{4}$ Università di Napoli, I-80125 Napoli, Italy

2-D OBSERVATIONS AT HIGH SPECTRAL RESOLUTION OF QUIET AREAS AND ACTIVE REGIONS ON THE SUN

D. Bonaccini ${ }^{1}$, G. Cauzzi ${ }^{2}$, A. Falchi ${ }^{1}$, R. Falciani ${ }^{3}$, L.A. Smaldone ${ }^{2}$, G.P. Tozzi ${ }^{1}$

1 Osservatorio Astrofisico di Arcetri, Largo E. Fermi 5, I-50125 Firenze, Italy

${ }^{2}$ Phys. Sciences Department, University of Naples, Italy

3 Astronomy Department, University of Florence, Italy

OBSERVATIONS WITH A BIREFRINGENT FILTER IN THE LINES Ba II $4554 \AA$ AND $\mathrm{H} \beta 4861 \AA$

V.I. Skomorovsky, V.E. Merkulenko, V.I. Poljakov

SibIZMIR, 664033 Irkutsk, USSR

POWER SPECTRA OF THE SOLAR CONVECTION

Dean-Yi Chou ${ }^{1}$, B.J. LaBonte ${ }^{2}$, D.C. Braun ${ }^{2}$, T.L. Duvall ${ }^{3}$

1 Phys. Department, Tsing Hua University, Hsinchu, 30043 Taiwan, R.O.C.

2 Inst. for Astronomy, University of Hawaii, Honolulu, Hawaii 96822, USA

${ }^{3}$ Laboratory for Astronomy and Solar Physics NASA/Goddard Space Flight Center, Greenbelt, MD, USA

STRUCTURAL PECULIARITIES OF FACULAR FIELDS

M.N. Stoyanova

Main Astronomical Observatory Ac.Sc. USSR, Pulkovo, 196140 Leningrad, USSR

THE COLOUR TEMPERATURE OF SUNSPOT FINE STRUCTURES

M.A. Aballe-Villero ${ }^{1}$, J.I. Garcia de la Rosa ${ }^{1}$, G.B. Scharmer ${ }^{2}$

${ }^{1}$ Instituto de Astrofisica de Canarias, E-38200 La Laguna, Tenerife, Spain

${ }^{2}$ Stockholm Observatory, S-13300 Saltsjöbaden, Sweden

III. Small-scale Magnetic Fields

ABOUT THE ACCURACY OF MEASUREMENTS OF THE MAGNETIC FIELD STRENGTH IN THE SOLAR PHOTOSPHERE BY THE LINE-RATIO METHOD A.V. Baranov, N.N. Baranova, S.C. Mozharovsky

Solar Station, 692533 Ussurijsk, USSR

DIAGNOSTICS OF THE FINE STRUCTURE OF MAGNETIC FIELDS IN THE PHOTOSPHERIC NETWORK AT THE PERIPHERY OF ACTIVE REGIONS

V.M. Grigoryev, V.L. Selivanov

SibIZMIR, 664033 Irkutsk, USSR

A CURVE OF GROWTH FOR THE NET CIRCULAR POLARIZATION OBSERVED IN FACULAE : COMPARISON THEORY - OBSERVATIONS

J. Sanchez Almeida, M. Collados, J.C. del Toro Iniesta

Instituto de Astrofisica de Canarias, E-38200 La Laguna, Tenerife, Spain 
A THERMODYNAMIC MODEL OF MAGNETIC FIELDS IN THE SOLAR PHOTOSPHERE

O.V. Chumak

Astrophysical Institute Ac.Sc. Kaz.SSR, 480068 Alma-Ata, USSR

A STATISTICAL STUDY OF THE SIZE AND FLUX SPECTRUM OF SMALL-SCALE MAGNETIC FIELDS

Wang Jingxiu, Shi Zhongxian, Liu Jianqiang, Han Feng, Liu Guilin

Beijing Astronomical Observatory, Chinese Academy of Sciences

OBSERVATIONS OF PHOTOSPHERIC MAGNETIC FIELDS WITH A NARROW-BAND TUNABLE FILTER

E.J. Kulagin

Main Astronomical Observatory Ac.Sc. USSR, Pulkovo, 196140 Leningrad, USSR

RING STRUCTURES OF THE TRANSVERSE MAGNETIC FIELD IN THE SOLAR PHOTOSPHERE

A.A. Pevtsov

SibIZMIR, 664033 Irkutsk, USSR

IV. Magnetohydrodynamics of the Photosphere

SYNERGETICAL ASPECT OF SOLAR MAGNETOHYDRODYNAMICS

E.I. Mogilevskij

Inst. of Terrestrial Magnetism, Ionosphere and Radio Wave Propagation

IZMIRAN, 142092 Troitsk, Moscow region, USSR

ABOUT SOME QUANTITATIVE CHARACTERISTICS OF PHOTOSPHERIC MHD TURBULENCE

V.I. Dolgopolov

Kiev University Astronomical Observatory, Observatornaya 3, 252053 Kiev, USSR

PHENOMENOLOGY OF LOCAL MAGNETIC STRUCTURES NEAR THE

PHOTOSPHERE : APPROACH IN TERMS OF SCALE SPECTRUM

N.N. Kontor

Inst. of Nuclear Physics, Moscow State University, Moscow 119899, USSR

DYNAMICS AND THERMODYNAMICS OF 3-D CONVECTION

Kwing L. Chan

Applied Research Corporation, Landover, MD, USA

SIMULATION OF SOLAR GRANULATION

U. Uus ${ }^{1}$, E.V. Poljakov ${ }^{2}$, V.N. Karpinsky ${ }^{2}$

${ }^{1}$ Inst. of Astrophysics and Physics of Atmosphere Ac.Sc. Est.SSR 202444 Tartu, USSR

2 Main Astronomical Observatory Ac.Sc. USSR, Pulkovo, 196140 Leningrad, USSR

ON THE APPLICABILITY OF A COMPACT DIFFERENCE HIGH ORDER ACCURACY SCHEME FOR THE NUMERICAL SIMULATION OF TURBULENT CONVECTION IN STELLAR ATMOSPHERES

I.N. Atroshchenko, A.S. Gadun

Main Astronomical Observatory Ac.Sc. Ukr.SSR, Goloseevo, 252127 Kiev, USSR 
THE ROLE OF THE PHOTOSPHERIC OSCILLATIONS AND CONCENTRATED MAGNETIC FIELDS IN THE HEATING OF THE CHROMOSPHERE

C.E. Alissandrakis ${ }^{1}$, H.C. Dara ${ }^{2}$, S. Koutchmy ${ }^{3}$

${ }^{1}$ University of Athens, 15783 Athens, Greece

2 Center for Astronomy and Applied Mathematics, 10673 Athens, Greece

${ }^{3}$ Institut d'Astrophysique de Paris, CNRS, 98 bis, Bd. Arago, F-75014 Paris, France

LINEAR WAVE TRANSFORMATION AND THE EXCITATION OF WAVES WITH SHORT WAVELENGTH

Yu.D. Zhugzhda, N.S. Dzahlilov

Solar Electrodynamic Sector, IZMIRAN, 142092 Troitsk, Moscow region, USSR

WAVE PROPAGATION IN MAGNETIC FLUX TUBES

S. Nasiri, Y. Sobouti

Department of Physics and Biruni Observatory, Shiraz, Iran

LONG NONLINEAR NON-AXISYMMETRIC SURFACE WAVE PROPAGATION IN A MAGNETIC TUBE

M.S. Ruderman

Inst. for Problems in Mechanics, Prospect Vernadskogo 101, 117526 Moscow, USSR

KINETIC ALFVÉN WAVES IN THE SOLAR ATMOSPHERE

Yu.M. Voytenko, A.N. Kryshtal, A.K. Yukhimuck

Main Astronomical Observatory Ac.Sc. Ukr.S.S.R., Goloseevo, 252127 Kiev, USSR

EXCITATION OF MAGNETIC FLUXTUBE OSCILLATIONS DURING SOLAR FLARES

V.V. Zaitsev

Inst. of Applied Physics Ac.Sc. USSR, Gorky, USSR

DIRECT MEASUREMENTS OF SHORT PERIOD TORSIONAL OSCILLATIONS OF SUNSPOTS

S.A. Druzhinin, A.A. Pevtsov, A.A. Levkovsky, M.V. Nikonova

SibIZMIR, 664033 Irkutsk, USSR

MAGNETOHYDRODYNAMIC DISTURBANCES IN SUNSPOTS

S.V. Kootz, P.P. Malovichko, A.K. Yukchimuk

Main Astronomical Observatory Ac.Sc. Ukr.SSR, Goloseevo, 252127 Kiev, USSR

INVESTIGATION OF THE DYNAMICS OF THE MAGNETIC FIELD AT THE

FORMATION OF SUNSPOTS, USING MAGNETOGRAMS

J. Linke ${ }^{1}$, J.H. Hernandez ${ }^{2}$, V.L. Selivanov ${ }^{3}$

1 IZMIRAN, 142092 Troitsk, Moscow region, USSR, and Zentralinstitut für Astrophysik, 1561 Potsdam,. DDR

2 Pedagogical High School, Inst. of Geophysics and Astronomy, Havana, Cuba

3 SibIZMIR, 664033 Irkutsk, USSR

ON THE EFFECT OF MAGNETIC FIELD BOUNDARIES IN COMPLEX SOLAR ACTIVE REGIONS

V.N. Ishkov, J. Linke

IZMIRAN, 142092 Troitsk, Moscow region, USSR

VARIATIONS OF PHYSICAL PARAMETERS AND OSCILLATORY MOTIONS IN SELECTED SUNSPOT GROUPS

Yu.A. Nagovitsin, G.F. Vyalshin

Main Astronomical Observatory Ac.Sc. USSR, Pulkovo, 196140 Leningrad, USSR 
DIAGNOSTICS OF SUNSPOT UMBRAL FINE STRUCTURE BY OSCILLATIONS

J. Staude ${ }^{1}$, Yu.D. Zhugzhda ${ }^{2}$, V. Locans ${ }^{3}$

1 Zentralinstitut für Astrophysik, DDR-1561 Potsdam

2 IZMIRAN, 142092 Troitsk, Moscow region, USSR

3 Radioastrophysical Observatory, 226524 Riga, USSR

Department of Physics, Ravishankar University, Raipur 492001, India

SEMI-EMPIRICAL MODELS OF UMBRAL LIGHT BRIDGES

M. Sobotka

Astronomical Institute of Czechoslovak Ac.Sc., 25165 Ondřejov, Czechoslovakia

MAGNETIC FIELD FRAGMENTATION IN FLUX TUBES IN SUBPHOTOSPHERIC LAYERS OF THE SUN

V.D. Kuznetsov

IZMIRAN, 142092 Troitsk, Moscow region, USSR

CURRENT SHEET MODEL OF A SUNSPOT

K. Jahn

Astron. Observatory of Warsaw University, Al. Ujazdowskie 4, 00-478 Warsaw, Poland

VERTICAL GRADIENTS OF SUNSPOT MAGNETIC FIELDS

A. Hofmann, J. Rendtel

Zentralinstitut für Astrophysik, Sonnenobservatorium Einsteinturm, DDR-1561 Potsdam

MAGNETIC FIELDS AND PROPER MOTIONS OF SUNSPOTS

M. Goshzhanov, V.I. Skazhenyuk

Physical-Technical Institute Ac.Sc. Tur.SSR, 744000 Ashkhabad, USSR

LARGE-SCALE PROPERTIES OF ACTIVE REGIONS

A. Hofmann

Zentralinstitut für Astrophysik, Sonnenobservatorium Einsteinturm, DDR-1561 Potsdam

INVESTIGATION OF THE INTEGRAL CHARACTERISTICS OF ACTIVE REGION MAGNETIC FIELDS

L.V. Ermakova

SibIZMIR, P.O. Box 4, 664033 Irkutsk, USSR

ON THE CONTINUUM INTENSITY-MAGNETIC FIELD RELATION DURING THE DECAY PHASE OF SUNSPOTS

V. Martinez-Pillet, M. Vazquez

Instituto de Astrofisica de Canarias, E-38200 La Laguna, Tenerife, Spain

THE EVOLUTION OF THE LONGITUDINAL MAGNETIC NEUTRAL LINE AND

CHROMOSPHERIC MATTER FLOWS IN SOLAR ACTIVE REGIONS

Zhang Hongqi, Ai Guoxiang, Li Jing, Liu Jainqiang

Beijing Astronomical Observatory, Chinese Academy of Sciences

TEMPORAL AND SPATIAL PROPERTIES OF THE Ca AND H $\alpha$ CHROMOSPHERIC NETWORK STRUCTURAL ELEMENTS

E.V. Kononovich, O.B. Smirnova

Sternberg State Astronomical Institute, Moscow University, 119899 Moscow, USSR

A STUDY OF DARK He-POINTS BY A TV METHOD

L.D. Parfinenko

Main Astronomical Observatory Ac.Sc. USSR, Pulkovo, 196140 Leningrad, USSR 
SOLVING THE MAGNETOHYDRODYNAMIC EQUATIONS IN THE STRONG FIELD APPROXIMATION

V.S. Gorbachev, S.R. Kel'ner

Moscow Physical Engineering Institute, Kashirskoe s. 31, 115409 Moscow, USSR

FLUCTUATIONS OF STRONG MAGNETIC FIELDS AS A CAUSE FOR THE FORMATION OF PLASMA CONDENSATIONS

V.S. Gorbachev, S.R. Kel'ner

Moscow Physical Engineering Institute, Kashirskoe s. 31, 115409 Moscow, USSR

SOLAR FORCE-FREE MAGNETIC FIELDS IN AND ABOVE THE PHOTOSPHERE

Chen Zhen Cheng, Cheng Yang

Beijing Astronomical Observatory, Chinese Academy of Sciences

FLOW VELOCITIES ALONG A SOLAR H $\alpha$ EMISSION LOOP

A.B. Delone, E.A. Makarova, G.A. Porfireva, E.M. Roschina, G.V. Yakunina

Sternberg State Astronomical Institute, Moscow University, 119899 Moscow, USSR

CORONAL PROLONGATION OF PHOTOSPHERIC STRUCTURES AND MAGNETIC FIELDS ACCORDING TO RADIO ASTRONOMY DATA

G.B. Gelfreikh

Main Astronomical Observatory Ac.Sc. USSR, Pulkovo, 196140 Leningrad, USSR

FINE STRUCTURE OF THE SOLAR ATMOSPHERE AND ITS CONVECTION INTO

THE INTERPLANETARY MEDIUM

G.P. Lyubimov

Institute of Nuclear Physics, Moscow University, 119899 Moscow, USSR

PHOTOSPHERIC MAGNETIC FIELDS AND CORONAL TEMPERATURES FROM ECLIPSE OBSERVATIONS

A.B. Delone, E.A. Makarova, G.V. Yakunina

Sternberg State Astronomical Institute, Moscow University, 119899 Moscow, USSR

"PERESTROIKA" OF MAGNETIC FIELDS IN ACTIVE REGIONS BEFORE A GREAT FLARE AND ITS MANIFESTATION IN THE RADIO RANGE

V.N. Borovik ${ }^{1}$, N.A. Drake ${ }^{2}$, A.A. Golovko ${ }^{3}$

${ }^{1}$ Main Astronomical Observatory Ac.Sc. USSR, Pulkovo, 196140 Leningrad, USSR

2 Astronomical Observatory, Leningrad University, Petrodvoretsk, 198904 Leningrad, USSR

${ }^{3}$ SibIZMIR, P.O. Box 4, 664033 Irkutsk, USSR

LARGE-SCALE CHANGES OF FILAMENT SYSTEMS CONNECTED WITH THE

APPEARANCE OF CORONAL TRANSIENTS AND GAMMA-RAY BURSTS

A.B. Delone, E.A. Makarova, V.S. Prokudina, G.V. Yakunina

Sternberg State Astronomical Institute, Moscow University, 119899 Moscow, USSR

PRELIMINARY RESULTS OF NON-LTE MODELLING OF FLUORESCENT IRON LINES IN SOLAR FLARES

N.A. Sakhibullin, U.Sh. Bayazitov

Kazan State University, Kazan, USSR

EMISSION IN THE LINES OF Fe I AND Fe II IN SOLAR FLARES

E.A. Baranovsky ${ }^{1}$, E.A. Kurochka ${ }^{2}$

${ }^{1}$ Crimean Astrophysical Observatory Ac.Sc. USSR, Nauchny, 334413 Crimea, USSR

2 Kiev University, $252053 \mathrm{Kiev}$, USSR

NON-THERMAL HYDROGEN IONIZATION IN ELEMENTARY FLARE BURSTS

V.V. Zharkova, V.A. Kobylisky

Kiev University, 252053 Kiev, USSR 


\section{Large-scale Structure and Dynamics}

THE "MAGNETIC FLUX-LIFETIME" DIAGRAM OF SOLAR MAGNETIC FEATURES OF DIFFERENT SCALES

A.A. Golovko

SibIZMIR, P.O.Box 4, 664033 Irkutsk, USSR

FORMATION AND EVOLUTION OF LARGE-SCALE MAGNETIC REGIONS OF

DOMINANT POLARITY (SECTORS) ON THE SUN

L.A. Plyusnina

SibIZMIR, P.O.Box 4, 664033 Irkutsk, USSR

STATISTICS OF LARGE-SCALE STRUCTURES OF THE SOLAR MAGNETIC FIELD

A. Antalová ${ }^{1}$, N. Stepanian ${ }^{2}$

1 Astronomical Institute of Slovak Ac.Sc., 05960 Tatranská Lomnica, Czechoslovakia

2 Crimean Astrophysical Observatory Ac.Sc. USSR, Nauchny, 334413 Crimea, USSR

THE LARGE-SCALE MAGNETIC FIELD OF THE SUN.

ROTATION, AND THE TOROIDAL AND RADIAL COMPONENTS

V.M. Grigoryev, S.M. Latushko, V.S. Peshcherov

SibIZMIR, P.O.Box 4, 664033 Irkutsk, USSR

PRESENTATION OF LARGE-SCALE MAGNETIC FIELDS ON THE SUN USING A RESTRICTED DATA SET

D.I. Ponyavin

Inst. of Physics, Leningrad University, 198904 Leningrad, USSR

ON SHORT-PERIOD VARIATIONS OF THE GLOBAL MAGNETIC FIELD OF THE SUN M.L. Demidov ${ }^{1}$, V.A. Kotov ${ }^{2}$, V.M. Grigoryev ${ }^{1}$

${ }^{1}$ SibIZMIR, P.O.Box 4, 664033 Irkutsk, USSR

${ }^{2}$ Crimean Astrophysical Observatory, Nauchny, 334413 Crimea, USSR

THE SOLAR MAGNETIC “MONOPOLE” IN ACTIVITY CYCLES $19-21$

V.M. Grigoryev, M.L. Demidov

SibIZMIR, P.O.Box 4, 664033 Irkutsk, USSR

GLOBAL MAGNETIC FIELD AND CORONAL ACTIVITY DISTRIBUTION DURING A TWENTY-TWO YEAR CYCLE

V. Bumba ${ }^{1}$, V. Rusin ${ }^{2}$

1 Astronomical Institute of Czechoslovak Ac.Sc., 25165 Ondřejov, Czechoslovakia

${ }^{2}$ Astronomical Institute of Slovak Ac.Sc., Stará Lesná, 05960 Tatranská Lomnica

CHARACTERISTICS OF SUNSPOT GROUPS AND THEIR MAGNETIC FIELDS

CORRESPONDING TO HARD X-RAY BURSTS WITH PEAK RATES

GREATER THAN 10'000 C/S

Zou Yi-xin, Chen Chuanle

Beijing Astronomical Observatory, Chinese Academy of Sciences

LARGE-SCALE MAGNETIC FIELD STRUCTURE IN QUIESCENT PROMINENCES

I.S. Kim ${ }^{1}$, V.Yu. Klepikov ${ }^{2}$, S. Koutchmy ${ }^{3}$, G. Stellmacher ${ }^{3}$, A.I. Stepanov ${ }^{2}$

${ }^{1}$ Sternberg State Astronomical Institute, Moscow University, 119899 Moscow, USSR

2 IZMIRAN, 142092 Troitsk, Moscow region, USSR

${ }^{3}$ Institut d'Astrophysique de Paris, CNRS, 98 bis, Bd. Arago, F-75014 Paris, France

ABOUT THE NATURE OF THE DIFFERENTIAL ROTATION OF THE SUN

V.F. Chistyakov

Ussurijsk Solar Station, 692533 Gornotajezhnoe, USSR 
DIAGNOSTICS OF THE SUBPHOTOSPHERIC DIFFERENTIAL ROTATION FROM OBSERVATIONS OF FIVE-MINUTE OSCILLATIONS

A.G. Kosovichev, K.V. Parchevsky

Crimean Astrophysical Observatory, Nauchny, 334413 Crimea, USSR

SOME PECULIARITIES OF THE DIFFERENTIAL ROTATION OF SUNSPOTS

DURING THREE SOLAR ACTIVITY CYCLES

M.Sh. Gigolashvili, E.V. Khutsishvili

Abastumani Astrophysical Observatory; Georgian Ac.Sc., 383762 Abastumani, USSR

CONVECTION AND DIFFERENTIAL ROTATION IN A CHEMICALLY

INHOMOGENEOUS CONVECTIVE ZONE

A.Z. Dolginov, A.V. Klyachkin

Ioffe Physical-Technical Institute Ac.Sc. USSR, 194021 Leningrad, USSR

GIANT CELLS ON THE SUN FROM SUNSPOT DISTRIBUTIONS AND MOTIONS

I. Sattarov

Astronomical Institute Ac.Sc. Uzbek.SSR, Tashkent-52, USSR

QUASI-BIENNIAL PERIODICITIES OF SOLAR ACTIVITY AS A MANIFESTATION

OF A GLOBAL CONVECTION MODULATION EFFECT

A.V. Mordvinov

SibIZMIR, 664033 Irkutsk, USSR

LARGE-SCALE FLOWS PRODUCED BY MAGNETIC FIELDS IN THE SOLAR CONVECTION ZONE

N.I. Kleeorin ${ }^{1}$, A.A. Ruzmaikin ${ }^{2}$

1 Lenin State Pedagogical Institute, 119435 Moscow, USSR

2 IZMIRAN, 142092 Troitsk, Moscow region, USSR

TORSIONAL OSCILLATIONS OF THE SUNSPOT ZONE

V.F. Chistyakov

Ussurijsk Solar Station, 692533 Gornotajezhnoe, USSR

ON THE POSSIBLE RELATION BETWEEN LONG-TERM LUMINOSITY VARIATIONS

AND THE INTERNAL ROTATION OF THE SUN

V.A. Kotov

Crimean Astrophysical Observatory, Nauchny, 334413 Crimea, USSR

ON THE POSSIBLE ORIGIN OF SOLAR VARIABILITY

I. Charvatova

Geophysical Institute Czechoslovak Ac.Sc., Bocni II, 14131 Praha, Czechoslovakia

\section{Generation of Solar Magnetic Fields}

ON THE NON-AXISYMMETRIC MAGNETIC FIELD MODES OF THE SOLAR DYNAMO

K.- H. Rädler ${ }^{1}$, A. Brandenburg ${ }^{2}$, I. Tuominen ${ }^{2}$

1 Zentralinstitut für Astrophysik, 1591 Potsdam, DDR

2 Observatory and Astrophys. Lab., University of Helsinki, SF-00130 Helsinki, Finland

SPATIAL DISTRIBUTION OF MAGNETIC ENERGY IN A SIMPLE TURBULENT DYNAMO

J.H.G.M. van Geffen, P. Hoyng

Laboratory of Space Research, Beneluxlaan 21, 3527 HS Utrecht, The Netherlands 
ON THE DIMENSION OF THE SOLAR ATTRACTOR

V.M. Ostryakov, I.G. Usoskin

Ioffe Physical-Technical Institute Ac.Sc. USSR, 194021 Leningrad, USSR

ON THE ORIGIN OF THE FINE-STRUCTURED SOLAR MAGNETIC FIELD

N.I. Kleeorin ${ }^{1}$, A.A. Ruzmaikin ${ }^{2}$, D.D. Sokoloff ${ }^{3}$

${ }^{1}$ Lenin State Pedagogical Institute, 119435 Moscow, USSR

2 IZMIRAN, 142092 Troitsk, Moscow region, USSR

3 Moscow University, 119899 Moscow, USSR

DYNAMO MECHANISM FOR ELECTRIC CURRENTS IN THE SOLAR ATMOSPHERE N. Seehafer

Zentralinstitut für Astrophysik, 1591 Potsdam, DDR

MODERN CONCEPTS OF THE SOLAR CYCLE

Yu.I. Vitinsky ${ }^{1}$, G.V. Kuklin ${ }^{2}$, V.N. Obridko ${ }^{3}$

${ }_{1}$ Main Astronomical Observatory Ac.Sc. USSR, Pulkovo, 196140 Leningrad, USSR

2 SibIZMIR, 664033 Irkutsk, USSR

3 IZMIRAN, 142092 Troitsk, Moscow region, USSR

EFFECT OF NEGATIVE MAGNETIC PRESSURE IN THE TURBULENT SOLAR CONVECTIVE ZONE

N.I. Kleeorin ${ }^{1}$, I.V. Rogachevsky ${ }^{2}$, A.A. Ruzmaikin ${ }^{3}$

1 Lenin State Pedagogical Institute, 119435 Moscow, USSR

2 Fedorov Institute of Applied Geophysics, 107258 Moscow, USSR

3 IZMIRAN, 142092 Troitsk, Moscow region, USSR

SOLAR CONVECTION: STRUCTURE AND ROLE IN SPOT FORMATION

A.V. Getling

Institute of Nuclear Physics, Moscow University, 119899 Moscow, USSR

TRANSFER OF SOLAR LARGE-SCALE MAGNETIC FIELDS BY THE

INHOMOGENEITY OF THE CONVECTION ZONE MATTER DENSITY

V.N. Krivodubskij

Astronomical Observatory, Kiev University, $252053 \mathrm{Kiev}$, USSR

ANOMALIES IN THE SOLAR ACTIVITY CYCLE

V. Martinez-Pillet, M. Vazquez

Instituto de Astrofisica de Canarias, E-38200 La Laguna, Tenerife, Spain

CHANGES IN THE LENGTH OF SOLAR CYCLES DURING THE LAST FIVE

CENTURIES

J. Strestik, I. Charvatova

Geophysical Institute Czechoslovak Ac.Sc., Bocni II, 14131 Praha, Czechoslovakia

THE SOLAR MAGNETIC FIELD ENERGY, CORONAL GREEN LINE EMISSION, AND SOME PROPERTIES OF THE CYCLE

V.P. Mikhailutsa, M.N. Gnevyshev

Main Astronomical Observatory Ac.Sc. USSR, Pulkovo, 196140 Leningrad, USSR 


\section{Convection and Magnetic Fields in Solar-type Stars}

STELLAR GRANULATION

D. Dravins ${ }^{1}, \AA$. Nordlund ${ }^{2}$

1 Lund Observatory, S-221 00 Lund, Sweden

2 Copenhagen University Observatory, DK-1350 Copenhagen, Denmark

MAGNETIC FIELDS AND OUTER ATMOSPHERES OF LATE-TYPE STARS

M.M. Katsova, M.A. Livshits

IZMIRAN, 142092 Troitsk, Moscow region, USSR

NON-LTE ANALYSIS OF THE CARBON SPECTRA OF THE SUN AND PROCYON

T.G. Shcherbina

Main Astronomical Observatory Ac.Sc. Ukr.SSR, Goloseevo, 252127 Kiev, USSR

OBSERVATION AND ANALYSIS OF THE NEUTRAL CALCIUM SPECTRUM OF THE SUN AND PROCYON

A.V. Perekhod, N.G. Stchukina

Main Astronomical Observatory Ac.Sc. Ukr.SSR, Goloseevo, 252127 Kiev, USSR

OVERIONIZATION OF NEUTRAL IRON IN THE ATMOSPHERES OF

SOLAR-LIKE SUBDWARFS

I.F. Bikmaev ${ }^{1}$, S. Bobritzkij ${ }^{2}$, N.A. Sakhibullin ${ }^{2}$

${ }^{1}$ Special Astrophysical Observatory, 357147 Nizhnij Arkhyz, USSR

2 Kazan University, 420008 Kazan, USSR 